УДК 316.776

$10.17213 / 2075-2067-2021-2-142-148$

\title{
УПРАВЛЕНИЕ РАЗВИТИЕМ ЦИФРОВОГО ПОТЕНЦИАЛА МОЛОДЕЖИ НА ОСНОВЕ КОНВЕРГЕНЦИИ ТЕХНОЛОГИЙ МЕНЕДЖМЕНТА, ОБРАЗОВАНИЯ И ИНФОРМАЦИОННО-КОММУНИКАЦИОННЫХ ТЕХНОЛОГИЙ
}

\author{
(C) 2021 г. . Р. Тимиргалеева , Н. В. Горбунова*, И. Ю. Гришин **
}

"Гуманитарно-педагогическая академия (филиал), Крымский федеральный университет имени В. И. Вернадского, г. Ялта, Россия

"* Московский государственный университет (филиал)

имени М. В. Ломоносова, г. Севастополь, Россия

Целью исследования стало обоснование необходимости и разработка комплексного механизма управления развитием ичиррового потенциала молодежи на основе интеграции конвергентных технологий менеджмента, образования и информационно-коммуникационных технологий.

Результаты исследования. Раскрыто содержание инструментария реализации иифррового потенциала молодежи, выявлены и проанализированы его основные преимущества, возможности и проблемы. Выделены и описаны основные функиии управления развитием ичифрового потенциала молодежи, реализаџия которых станет основой формирования цифрровых компетенций и цүифровой культуры молодежи, раскроет их способности к циифровому взаимодействию.

Ключевые слова: ичифровой потенцииал молодежи; информациионно-коммуникационнье технологии; управление развитием; безопасность ичифрового взаимодействия; медиаграмотность; ичифровые медиа.

\section{MANAGING YOUTH DIGITAL POTENTIAL DEVELOPMENT BASED ON THE CONVERGENCE OF MANAGEMENT TECHNOLOGIES, EDUCATION AND INFORMATION AND COMMUNICATION TECHNOLOGIES}

\author{
(C) 2021 R. R. Timirgaleeva*, N. V. Gorbunova*, I. Y. Grishin ${ }^{* *}$ \\ "Humanities and Education Science Academy (branch), \\ Vernadsky Crimean Federal University, Yalta, Russia \\ ${ }^{* *}$ Lomonosov Moscow State University (branch), Sevastopol, Russia
}

The aim of the study was to substantiate the need for and develop an integrated mechanism for managing the development of the digital potential of youth based on the integration of convergent technologies of management, education and information and communication technologies.

The results of the study. The content of the toolkit for realizing the digital potential of youth is revealed, its main advantages, opportunities and problems are identified and analyzed. The main functions of managing the development of the digital potential of youth are highlighted and described, the implementation of which will become the basis for the formation of digital competencies and digital culture of young people, and will reveal their ability to digital interaction. 
Key words: digital potential of youth; information and communication technologies; development management; security of digital interactions; media literacy; digital media.

Актуальность и постановка проблемы. На современном этапе перехода Российской Федерации к передовым цифровым технологиям, интеллектуальным производственным технологиям, роботизированным системам, новым материалам и способам конструирования, создания систем обработки больших объемов данных, машинного обучения и искусственного интеллекта степень развития цифрового потенциала молодежи как основного ресурса, обеспечивающего эффективную реализацию данных процессов, становится важнейшим фактором формирования национальной конкурентоспособности. Развитие цифрового потенциала молодежи является серьезным стимулом социальноэкономического роста и развития общества, занятости населения, расширения конкуренции. Сегодня уровень развития потенциала молодежи определяет не только экономический потенциал страны, качество жизни, социальное благополучие и развитие общества, а также роль и место страны в глобальном обществе, масштабы и перспективы социальноэкономической интеграции.

В данном контексте особую актуальность приобретают междисциплинарные исследования, направленные на разработку моделей и методов оценки эффективности инвестиций в потенциал молодежи, выявление особенностей формирования и структуры человеческого капитала в России, моделирование сценариев его развития. Разработка комплексной модели развития потенциала молодежи, основанной на конвергенции технологий менеджмента, образования и интеллектуальных информационных технологий, является новой по постановке и важной для практического применения полученных результатов. Данные аспекты определили актуальность исследования.

Цель исследования - обоснование необходимости и разработка комплексного механизма управления развитием цифрового потенциала молодежи на основе интеграции конвергентных технологий менеджмента, образования и информационно-коммуникационных технологий.

Изложение основного материала исследования. Для современной молодежи информационно-коммуникационные технологии (ИКТ) уже стали не просто неотъемлемой частью жизни, они пронизывают практически все ее сферы. Цифровые технологии, став частью современной повседневной жизни, внесли определенный вклад в развитие инноваций и общества, расширили возможности молодежи в доступе к информации, развитию личностных компетенций, установлению взаимодействия друг с другом независимо от места положения, социального статуса, ограниченности в состоянии здоровья и т.п. Кроме того, современные ИКТ привели к экономическим, социальным и культурным изменениям в жизни молодых людей, сформировав по сути новое «цифровое» поколение, получившее новые возможности для жизни, учебы, трудовой деятельности (Е.Н. Чижова, Л.И. Журавлева, И.А. Монастырская) [5].

Отмечая целый ряд позитивных перемен, нельзя не обратить внимание на появление новых рисков, связанных с получением, хранением, обработкой и передачей данных. ИКТ могут оказать негативное воздействие на психическое и физическое здоровье молодежи. Представляет определенную угрозу чрезмерная вовлеченность, попадание молодежи в зависимость от информационных и игровых технологий. Это обусловлено тем, что у современной молодежи, родившейся в информационном обществе, не сформирована цифровая культура. У молодых людей прослеживается явное несоответствие (разрыв) между восприятием своих цифровых навыков и способностью безопасно использовать современные информационно-коммуникационные технологии, а также правильно ориентироваться в информационном пространстве. Поспособствовала этому процессу и пандемия, которая заставила практичес- 
ки все население страны организовать свое обучение, работу и досуг посредством ИКТ (Р.Р. Тимиргалеева, И. Ю. Гришин) $[3,4]$.

Организация образовательного процесса в высшей школе в период пандемии осуществлялась с использованием дистанционных образовательных технологий. Переход к работе в онлайн-формате обусловил необходимость поиска и использования новых «цифровых» форм работы со студенческой молодежью, создания электронной образовательной среды, необходимость развития информационно-коммуникационной компетенции профессорско-преподавательского состава (Н. В. Горбунова, А. В. Глузман) $[2,9]$.

Вместе с тем развитием цифрового потенциала молодежи необходимо последовательно и целенаправленно управлять, в том числе формировать цифровую культуру и безопасность (С. Б. Шапошник) [8].

Опираясь на социологическую трактовку термина «потенциал» (целостное представление о находящихся в резерве латентных возможностях того или иного объекта, которые способны реализоваться при благоприятно разворачивающихся условиях), под цифровым потенциалом молодых людей будем понимать качества и возможности молодого поколения разумно и безопасно использовать цифровые технологии, что предполагает организационную поддержку технического обеспечения, внедрения инновационных активностей и содержательного информационного наполнения онлайн-взаимодействия во всех сферах жизни молодежи. Данный термин описывает сферу деятельности молодежи, которая использует цифровые медиа и новейшие технологии для развития обще- ства. Также термин может быть использован для описания работы молодежи, которая реализуется в социальных группах, в онлайнсреде. По сути, мы получаем цифровую деятельность молодежи, которая является новым форматом взаимодействия.

При этом отметим, что цифровая деятельность молодежи, реализуемая посредством ее цифрового потенциала, может использовать достаточно широкий инструментарий и активности (таблица 1).

Управление развитием цифрового потенциала молодежи предполагает комплексное и непрерывное использование цифровых активностей и инструментов, которые можно объединить в три группы: цифровые медиа, STEAM-образование, социальные сети и онлайн-контент, 3-Д и виртуальная реальность. Поскольку информационно-коммуникационные технологии меняются и развиваются достаточно быстро, претерпевают изменения и инструменты, поэтому цифровой потенциал молодежи необходимо развивать постоянно, чтобы молодые люди всегда успевали за развитием технологий и своевременно осваивали новые технологические навыки владения ими (Л. Д. Сайфуллина) $[6,7]$.

Отметим также, что каждый цифровой инструмент и активность дают значительные возможности для цифрового развития молодежи, но при этом нельзя забывать о появлении новых вызовов и рисков, с ними связанных, поэтому вместе с развитием цифровых навыков и компетенций необходимо обеспечить формирование у молодежи безопасного поведения в интернет-пространстве, что предполагает развитие умений анализировать риски и последствия, принимать обосно-

Таблица 1

\section{Инструментарий реализации цифрового потенциала молодежи}

\begin{tabular}{|l|l|}
\hline $\begin{array}{l}\text { Инструменты: интернет-ресурсы, } \\
\text { онлайн-ресурсы }\end{array}$ & \multicolumn{1}{|c|}{$\begin{array}{c}\text { Средства, обеспечивающие взаимодействие } \\
\text { и доступ к информации, ее обмену, передаче и т.п. }\end{array}$} \\
\hline Активности & $\begin{array}{l}\text { Методы, формы и другие активности, для внедрения ко- } \\
\text { торых используются интернет-ресурсы (онлайн-ресурсы) }\end{array}$ \\
\hline $\begin{array}{l}\text { Информационный контент } \\
\text { (информация, цифровые ресурсы) }\end{array}$ & $\begin{array}{l}\text { Любая информация, размещенная на сайте, в блоке } \\
\text { пользователя, на странице в социальной сети, исполь- } \\
\text { зуемая для работы в сети Интернет (фотографии, видео, } \\
\text { объекты виртуальной реальности и интерактивного мо- } \\
\text { делирования, инфографика и т.п.) }\end{array}$ \\
\hline
\end{tabular}


ванные решения и принимать на себя ответственность за их последствия. Для этого молодые люди должны владеть элементарными знаниями рисков в сети Интернет и средствами их профилактики, предупреждения рисковых и опасных ситуаций. Получить данные знания молодежь может как самостоятельно, так и с помощью средств неформального образования (курсы, учебные программы в интернете и т.д.). При этом безопасное и эффективное использование цифровых медиа и новых информационно-коммуникационных технологий представляют собой эффективный инструментарий развития цифрового потенциала молодежи (С.А. Влазнева, В. М. Володин, И. А. Питайкина) [1].

Таким образом, развитие цифрового потенциала молодежи дает следующие возможности:

- возможность общаться, контакты и включенность в общество;

— возможность учиться в любое удобное для себя время и в удобном для себя месте, приобретение новых знаний и навыков;

— творческая реализация (фото, дизайн, аудио- и видео-продукты);

- трудовая активность;

- доступный инструмент для контактов;

- доступный инструмент для исследования процессов и результатов деятельности молодежи;

— возможность повышения квалификации и получения новых знаний, умений, навыков и компетенций.

Определим основные функции управления развитием цифрового потенциала молодежи:

- информационная функция - играет ключевую роль в становлении и функционировании современного информационного общества, основной составляющей которой является молодежь. Реализация информационной функции предполагает своевременное и полное информирование молодежи о тенденциях и перспективах развития технологий коммуникации, о возможных угрозах и рисках. Кроме того, своевременная и релевантная информация позволяет принимать эффективные управленческие решения;

- образовательная функция - реализуется посредством обучения молодежи по следующим направлениям развития цифрового потенциала: цифровая грамотность, общественная грамотность, получение новых знаний и навыков. При этом цифровая грамотность предполагает обучение по таким аспектам цифровой информации, как безопасность в интернете, работа с большим массивом данных (Big Data), медиаграмотность. Медиаграмотность предполагает формирование у молодежи сознательного восприятия онлайн-контекста, умения получать наиболее важную, ценную и полезную информацию в онлайн-контенте, принимать активное участие в медиапроцессе, а также уметь защищаться от деструктивной информации. Общественная грамотность представляет собой обеспечение молодежи информацией относительно общественной среды (правовая осведомленность, формирование гражданской сознательности, знание своих возможностей и т.п.);

- коммуникативная функция - связывает все функции управления и обеспечивает формирование коммуникативных сетей;

- социализирующая функция - проявляется в формировании духовного мира молодого человека, его ценностных ориентаций и стереотипов молодого поколения.

При этом отметим, что все перечисленные функции тесно связаны между собой и, как правило, реализуются в комплексе.

Заключение. Подводя итоги, отметим, что для безопасной и эффективной деятельности с использованием цифровых технологий молодежь должна быть компетентной и грамотной в цифровом аспекте, в полной мере иметь возможность реализовать свой цифровой потенциал. Ошибочным является мнение, что достаточно просто квалифицированно использовать современные цифровые технологии, не умея в полном объеме владеть цифровыми знаниями и навыками, необходимыми для успешного обучения и трудоустройства, технологиями и методами защиты личной информации в интернете. Данные аспекты подтверждают необходимость управления развитием цифрового потенциала молодежи, которая не только сама должна овладеть соответствующими навыками и компетенциями, но и быть способной учить молодое поколение цифровой грамотности, являющейся основой для возможности использования цифровых медиа детьми и молодежью, грамотно реализовывать и за- 
щищать свои права в сети Интернет, быть способными к цифровому сотрудничеству, обеспечению безопасности и грамотному решению возникающих проблем в процессе цифрового взаимодействия.

\section{Литература}

1. Володин В.М., Питайкина И.А., Влазнева С.А. Влияние цифровой экономики на трансформацию человеческого капитала // Экономические науки. - 2018. №6(163). - С. 44-48.

2. Горбунова Н.В., Глузман А.В. Дистанционное образование: реалии и перспективы // Гуманитарные науки (г. Ялта). №2 (50). - 2020. - С. 51-57.

3. Интеллектуальная модель формирования индивидуальной образовательной траектории в условиях цифровой экономики / Тимиргалеева Р. Р. // Наука и мир. - 2020. T. 1. — №8 (84). - C. 71-75.

4. Концепция формирования интеллектуального образовательного навигатора / Тимиргалеева Р.Р., Гришин И.Ю. В сборнике: Информационные системы и технологии в моделировании и управлении. Сборник трудов V Международной научно-практической конференции. - 2020. - С. 437-443.

5. Цифровая экономика и ее роль в управлении современными социально-экономическими отношениями / Е.Н. Чижова, Л.И. Журавлева, И.А. Монастырская и др.; под ред. проф. Е.Н. Чижовой. - Белгород: Изд-во БГТУ, 2015. - 392 с.

6. Сайфуллина Л.Д. Управление человеческим капиталом в системе цифровых экономических отношений [Электронный ресурс] // Фундаментальные исследования. - 2018. №11-1. - С. 92-96. - Режим доступа: http:/www.fundamental-research.ru/ru/article/ view?id=42306 (Дата обращения: 26.05.2019).

7. Человеческий капитал в формате цифровой экономики: Междунар. науч. конф., посвященная 90-летию С.П. Капицы, Москва (16 февраля 2018 г.): сб. докладов. - М.: Редакционно-издательский дом РосHOУ, 2018. - $432 \mathrm{c}$.

8. Шапошник С.Б. Научное сообщество как фактор развития информационного общества в регионах России // Информационное общество. — 2017. — №4-5. - С. 95-101.
9. Gorbunova N., Vaganova O., Smirnova Z., Chelnokova E., Gorbunova N., Kirillova I. Choosing an e-course architecture, International Journal of Advanced Trends in Computer Science and Engineering [Electronic resource]. - 2020. Vol. 9. - №3. - P. 2679-2683. - URL: https:// www.elibrary.ru/item.asp?id=43309202.

\section{References}

1. Volodin V.M., Pitajkina I.A., Vlazneva $S$. A. Vlijanie cifrovoj jekonomiki na transformaciju chelovecheskogo kapitala [The impact of the digital economy on the transformation of human capital] // Jekonomicheskie nauki [Economic sciences]. — 2018. — №6 (163). Pp. 44-48.

2. Gorbunova N.V., Gluzman A.V. Distancionnoe obrazovanie: realii i perspektivy [Distance education: realities and prospects] // Gumanitarnye nauki [Humanities] (g. Jalta). №2 (50). - 2020. - Pp. 51-57.

3. Intellektual'naja model' formirovanija individual'noj obrazovatel'noj traektorii v uslovijah cifrovoj jekonomiki [Intellectual model of the formation of an individual educational trajectory in the conditions of the digital economy] / Timirgaleeva R. R. // Nauka i mir [Science and world]. - 2020. — Vol. 1. — №8 (84). Pp. 71-75.

4. Koncepcija formirovanija intellektual'nogo obrazovatel'nogo navigatora [The concept of forming an intelligent educational navigator] / Timirgaleeva R.R., Grishin I. Ju. V sbornike: Informacionnye sistemy i tehnologii $\mathrm{v}$ modelirovanii i upravlenii. Sbornik trudov V Mezhdunarodnoj nauchno-prakticheskoj konferencii [In the collection: Information systems and technologies in modeling and management. Collection of proceedings of the V International Scientific and Practical Conference]. - 2020. - Pp. 437-443.

5. Cifrovaja jekonomika i ee rol' v upravlenii sovremennymi social'no-jekonomicheskimi otnoshenijami [Digital economy and its role in the management of modern socio-economic relations]/ E.N. Chizhova, L.I. Zhuravleva, I.A. Monastyrskaja i dr.; in prof. E. N. Chizhova (eds.). - Belgorod: Izd-vo BGTU, 2015. $392 \mathrm{p}$.

6. Sajfullina L.D. Upravlenie chelovecheskim kapitalom v sisteme cifrovyh jekonomicheskih otnoshenij [Management of human cap- 
ital in the system of digital economic relations] [Jelektronnyj resurs] // Fundamental'nye issledovanija [Fundamental Research]. — 2018. №11-1. — Pp. 92-96. — URL: http://www.fundamental-research.ru/ru/article/view?id=42306 (Date accessed: 26.05.2019).

7. Chelovecheskij kapital v formate cifrovoj jekonomiki: Mezhdunar. nauch. konf., posvjashhennaja 90-letiju S.P. Kapicy, Moskva (16 fevralja 2018 g.): sb. dokladov [Human capital in the digital economy: International scientific conferencededicated to the 90th anniversary of S. P. Kapitsa, Moscow (February 16, 2018): collection of reports]. - Moscow: Redakcionnoizdatel'skij dom RosNOU, 2018. - 432 p.
8. Shaposhnik S. B. Nauchnoe soobshhestvo kak faktor razvitija informacionnogo obshhestva $\mathrm{v}$ regionah Rossii [Scientific community as a factor in the development of information society in the regions of Russia] // Informacionnoe obshhestvo [Information Society]. — 2017. №4-5. - Pp. 95-101.

9. Gorbunova N., Vaganova O., Smirnova Z., Chelnokova E., Gorbunova N., Kirillova I. Choosing an e-course architecture, International Journal of Advanced Trends in Computer Science and Engineering [Electronic resource]. - 2020. Vol. 9. - №3. - P. 2679-2683. - URL: https:// www.elibrary.ru/item.asp?id=43309202.

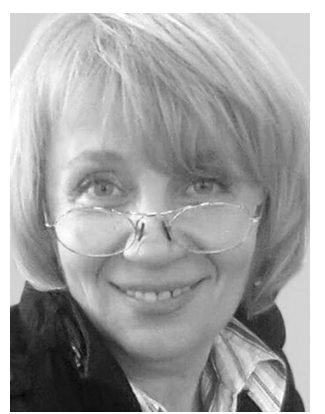

28635 , г. Ялта, ул. Севастопольская, 2a

2a Sevastopolskaya st., 28635, Yalta, Russia

E-mail: renatimir@gmail.com 


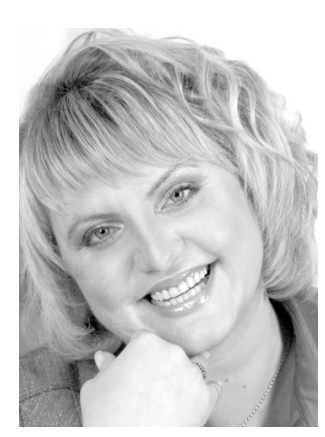

Горбунова Наталья Владимировна - доктор педагогических наук, профессор, директор Гуманитарно-педагогической академии (филиала) Крымского федерального университета им. В. И. Вернадского в г. Ялте.

Gorbunova Nataliia Vladimirovna - Doctor of Pedagogical Sciences, Professor, Director of the Humanities and Education Science Academy (branch), Vernadsky Crimean Federal University in Yalta.

28635, г. Ялта, ул. Севастопольская, 2а 2a Sevastopolskaya st., 28635, Yalta, Russia

E-mail: natalya-gor2008@yandex.ru

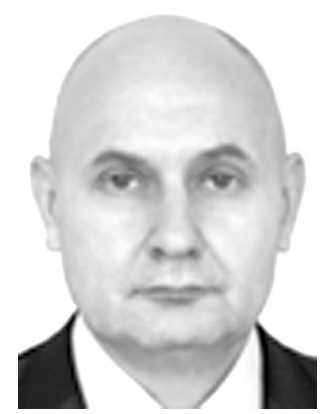

Гришин Игорь Юрьевич - доктор технических наук, профессор, заместитель директора по научной работе Московского государственного университета (филиала) имени М.В.Ломоносова в г. Севастополе.

Grishin Igor Yurevich - Doctor of Engineering Sciences, Professor, Deputy Director for Scientific Work, Lomonosov Moscow State University (branch) in Sevastopol.

299000 , г. Севастополь, ул. Героев Севастополя, 7

7 Geroev Sevastopolya st., 299000, Sevastopol, Russia

E-mail: igugri@gmail.com 